\title{
Development and research of seeding devices for selected self- propelled pneumatic seeder
}

\author{
Nikolay Pavlovich Kryuchin, Dmitry Nikolaevich Kotov*, Alexander Nikolaevich Andreev, Olga Alexandrovna \\ Artamonova
}

Samara State Agrarian University, 2 Uchebnaya St., townlet Ust-Kinelsky, Kinel, 446442, Samara region, Russia

\begin{abstract}
This paper proposes the use of a self-propelled pneumatic mini-seeder with replaceable mechanical seeding devices for selection production conditions. As a result of the research carried out, operating high-tech designs of seeding devices with a continuous dosing principle of auger and torsion-pin types have been designed and manufactured. The sowing devices allow sowing loose and difficult-to-flow seeds when used as dispensers on a self-propelled pneumatic mini-seeder for sowing herbs in breeding production. The developed seeding devices will significantly reduce the range of seeders and expand the range of sown seeds of various agricultural plants with one brand of seeding machine.
\end{abstract}

\section{Introduction}

The peculiarities of the mechanization of the cultivation of crops in breeding production are the use of small plots at all stages of breeding and primary seed production, the requirement for high-quality sowing of seeds, and the exclusion of macro and micro damage to the expensive seed. Along with this, quite a lot of different types and brands of machines are required with their often singleuse at each separate stage of the breeding process. In addition, the variety of crops sown requires the use of seeding machines equipped with seeding systems, highly specialized for one or two types of seeds.

Therefore, the development of machines for the mechanization of work in breeding, variety testing, and primary seed production presents a certain difficulty.

It is possible to significantly reduce the range of seeders and expand the range of sown seeds of various agricultural plants with one brand of a sowing machine by using a universal self-propelled small-sized base based on the use of a pneumatic seeding system with replaceable mechanical seeding devices adapted to the conditions of selection production [1-3].

\section{Materials and methods}

Seeds of cereal and leguminous grasses are in a wide range of characteristics in terms of size, the density of kernels, and windage, therefore, due to the impossibility of metering seeds with one sowing device, sowing of various grasses with one seeder has not been implemented in practice. In addition, the seeds of leguminous grasses for swelling and germination require an increased amount of moisture and its lack in the spring leads to a delay in the emergence and sparseness of seedlings. It is possible to partially solve the problem of lack of moisture in the initial period of growth by sowing with soaked seeds, however, as a result of soaking, the seeds acquire the property of cohesion, passing into the category of difficult-flowing ones, which requires special seeding devices.

These circumstances require the availability of seeding machines not only for various crops but also for sowing a separate category of seeds, which significantly increases the cost of selection production since the duration of operation of seeders during the year can be only a few hours.

Regarding pilot production on small plots, seeding devices can have small overall dimensions, and the use of an electric drive will allow the use of quick-mounted central metering seeders.

To assess the possibilities of implementing a selfpropelled seeder in the design and technological scheme, we analyzed and developed a classification scheme for various types of seeding devices for dosing grass seeds (Fig. 1).

Based on the experience in the development of seeding devices, applying the experience of existing studies [4-8], the authors of the article designed and manufactured mechanical seeding devices of auger (see Fig. 2) and torsion-pin (see Fig. 3) types for the equipment of a self-propelled pneumatic seeder for seeding various grasses.

The main advantage of the auger sowing device [9] is the ability to dose bulk seeds with high quality. At the same time, in conditions of sowing with a seeder with a working width of one meter, it is possible to use replaceable auger elements for sowing small-seeded and medium-seeded crops made on a $3 \mathrm{D}$ printer.

The auger sowing device contains a housing of a sowing device 1 , a casing of the auger 2 with an outlet

\footnotetext{
* Corresponding author: kotov_d@bk.ru
} 
window 3, a metering auger 4 . There is a removable hopper 6 installed in the receiving chamber of the sowing device, with flat spring-loaded dampers 5 made in the lower base of the hopper with the possibility of rotation about the axes.

The auger sowing device works as follows. Seed material prepared for sowing, in the amount necessary for sowing a plot, is poured into a removable hopper 6 . At the same time, thanks to the tension springs, shutters
5 are in a closed state, excluding the spilling of seed from the removable hopper.

After that, the removable hopper 6 is inserted into the receiving chamber, while flaps 5 are rotated at a predetermined angle, greater than the angle of repose, opening access for moving the seed along the surface of the flaps along the sidewalls of the receiving chamber to its bottom.

\section{Grass Seed Metering Equipment}

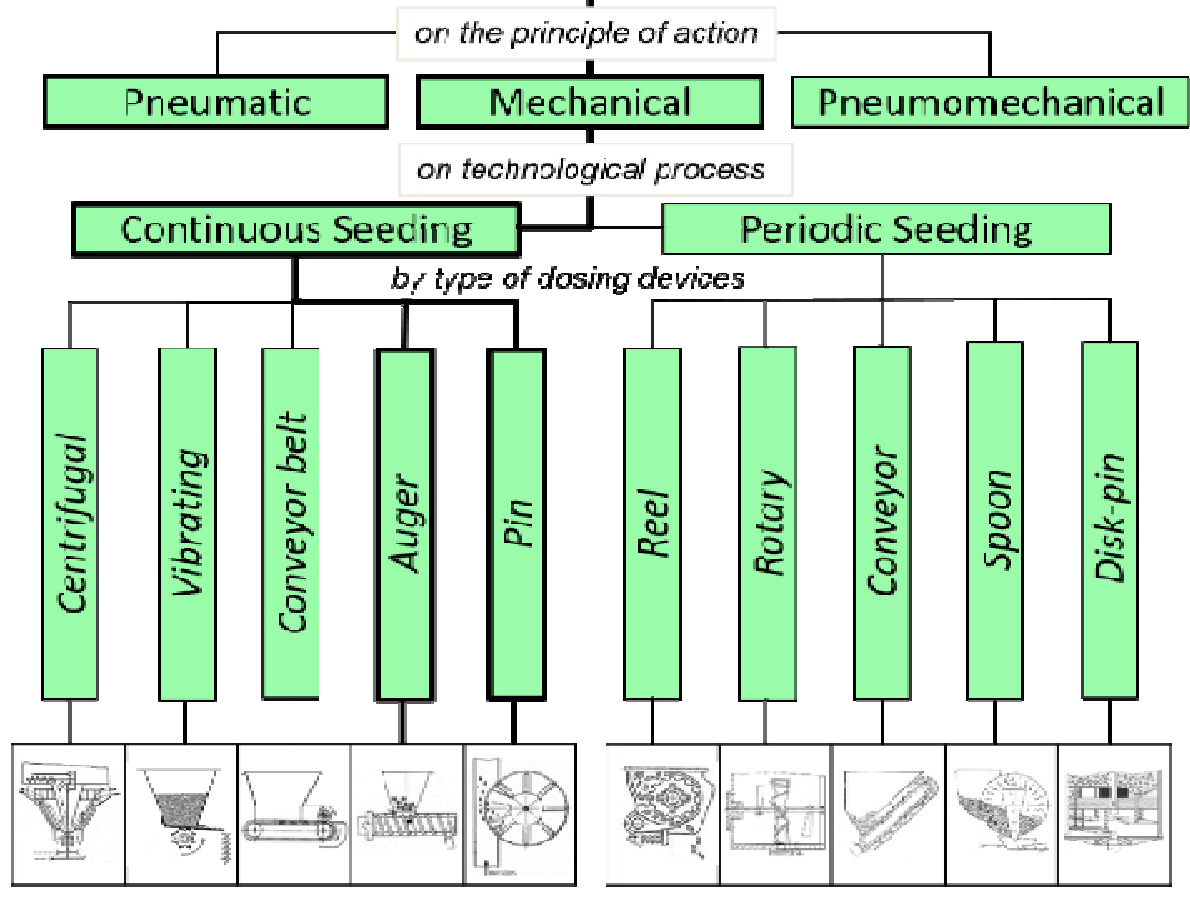

Fig. 1. Classification of seeding devices for sowing grass seeds

After the start of the movement of the seeder, the rotating metering auger 5 of the sowing device will carry the seed outside the auger casing 2, freeing up the volume to fill it with seed coming from the removable hopper 6 . The location of the valves 5 in the open state above the metering auger 4 at an angle greater than the angle of repose, ensures stable continuous movement of seed material and eliminates the influence of the seed level in the hopper on the metering accuracy.

For sowing difficult-flowing and related sowing materials, in particular soaked seeds of leguminous grasses, a torsion-pin sowing device was developed and created [10], containing a hopper 1 with a seeding slot 2 and horizontal pins 3 , which are fixed on the drive shaft 7. On the outer cylindrical surface of the horizontal pins 3 is made of a few movable pins 4 located at some distance from each other.

The sowing device works as follows. The seeds from hopper 1 under the action of gravity fill the space between the horizontal pins 3 . When the drive shaft 7 rotates, the movable pins 4 , which are in a vertical position, capture the seed layer and form the combined action with the horizontal pins 3 in front of them in the direction of rotation, the volume of seeds, which moves into the space between the visor 6 and the bottom of the sowing unit 5. After contact with visor 6 , the movable pins 4 are deflected in the direction opposite to the rotation of the drive shaft 7 . The volume of seeds formed by the pins is pushed along the bottom of the sowing unit 5 to the border of the seeding window 2, through which they are poured into the funnel of the seed tube 8 . With further movement, the movable pins 4 slide along the lower surface of the visor 6 in a deflected state until they exit to the seed capture zone, where they return under the action of torsion springs to their original vertical position, after which the working cycle is repeated. 

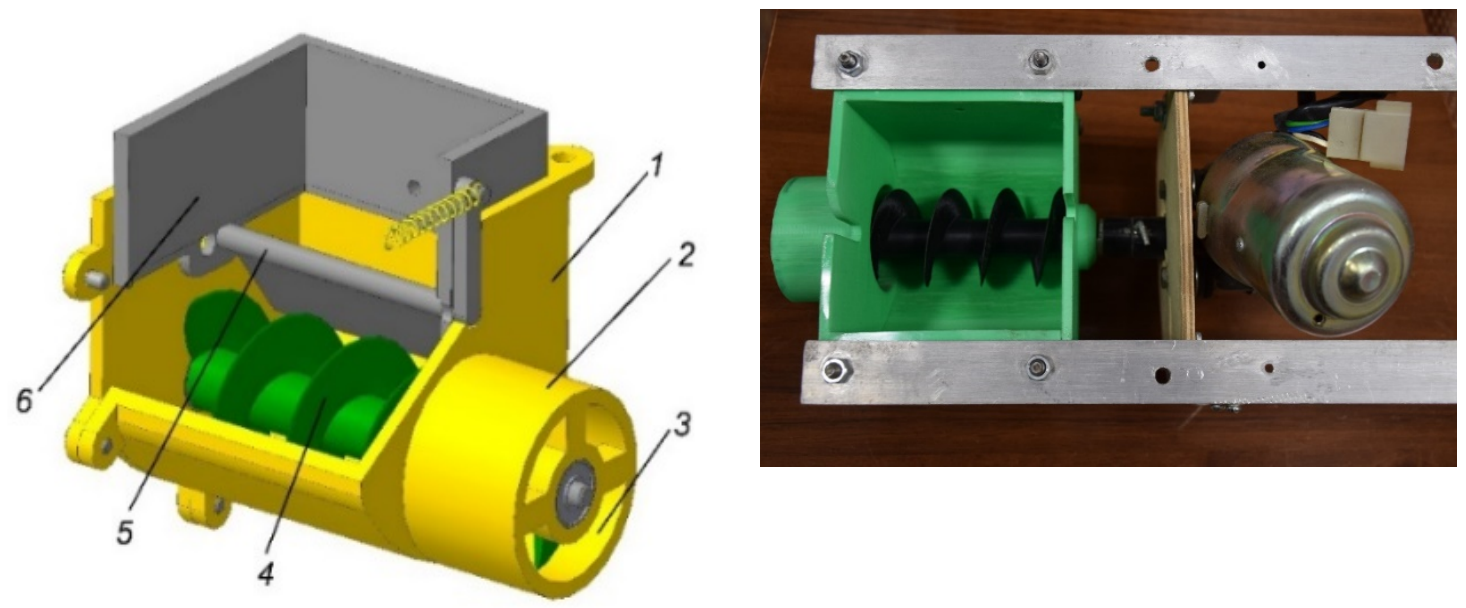

Fig. 2. Auger seeding device: a - 3D - model; b - general view with an electric drive, (the bunker is removed): 1 - case; 2 - casing; 3 - outlet window; 4 - dosing screw; 5 - damper; 6 - removable hopper

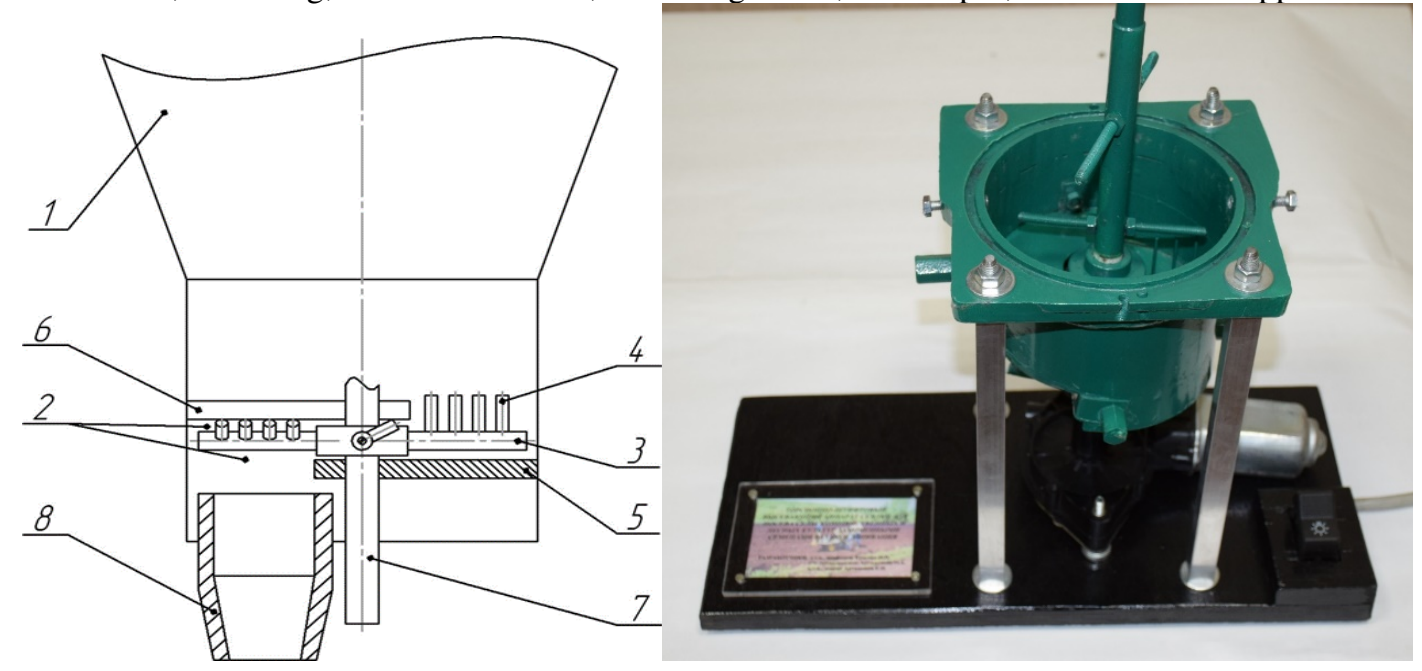

Fig. 3. Diagram of the torsion-pin sowing device: a - diagram; b - general view with an electric drive: 1 - seed hopper; 2 - seeding window; 3 - horizontal pins; 4 - movable pins; 5 - the bottom of the sowing device; 6 - visor; 7 - drive shaft; 8 - funnel of the seed tube

\section{Results and discussion}

Determination of the dependence of the seed supply and the instability of seeding on the rotational speed of the auger is necessary to establish the limiting values of the rotational speeds at which a linear dependence is maintained and the values of instability of seeding are achieved, which do not exceed the agrotechnical requirements for a given type of seed.

The process of operation of the auger sowing apparatus was investigated on the sowing of fine-seeded material of the cereal forage crop Mogar, the average value of the mass of 1000 seeds, which was $3.1 \mathrm{~g}$.

Seed supply and seeding instability were determined by changing the value of the screw rotation frequency from 5 to $25 \mathrm{rpm}$. The installation angle of the dampers relative to the horizontal level of the location of the lower edges of the bunker was fixed at 30 degrees.

Based on the research results, graphical dependences of the influence of the auger rotation speed on the auger productivity and the instability of seeding were built (see Fig. 4).
Analyzing the dependence of the feed of the sown material on the rotational speed of the auger shaft, it is necessary to conclude that a proportional increase in the feed of seeds with an increase in the rotational speed of the auger occurs up to a certain value, then the feed of the sown material is stabilized. The maximum feed rate corresponds to the screw speed values close to $25 \mathrm{rpm}$.

The instability of seeding auger sowing apparatus, in the range of auger rotation frequencies from 5 to $20 \mathrm{rpm}$, did not exceed $3 \%$, which corresponds to agrotechnical requirements for sowing loose small-seeded seed.

Based on the results obtained, it is necessary for further research, as well as in practical use, when adjusting to a given seeding rate, to limit the auger speed to $20 \mathrm{rpm}$.

Investigations of the supply and instability of seeding with a torsion-pin seeding device were carried out to study the process of dosing of soaked seeds and to clarify its design parameters. Soaked seeds of the annual white sweet clover variety Srednevolzhsky were used as a seed for research. 
The experiments were carried out on a torsion-pin sowing device with 4 torsion-pin groups, on the radial fingers of which three movable pins $15 \mathrm{~mm}$ high were installed, with an installation height of the upper segment equal to $18 \mathrm{~mm}$, with a change in the drive shaft speed from 10 to $40 \mathrm{rpm}$.

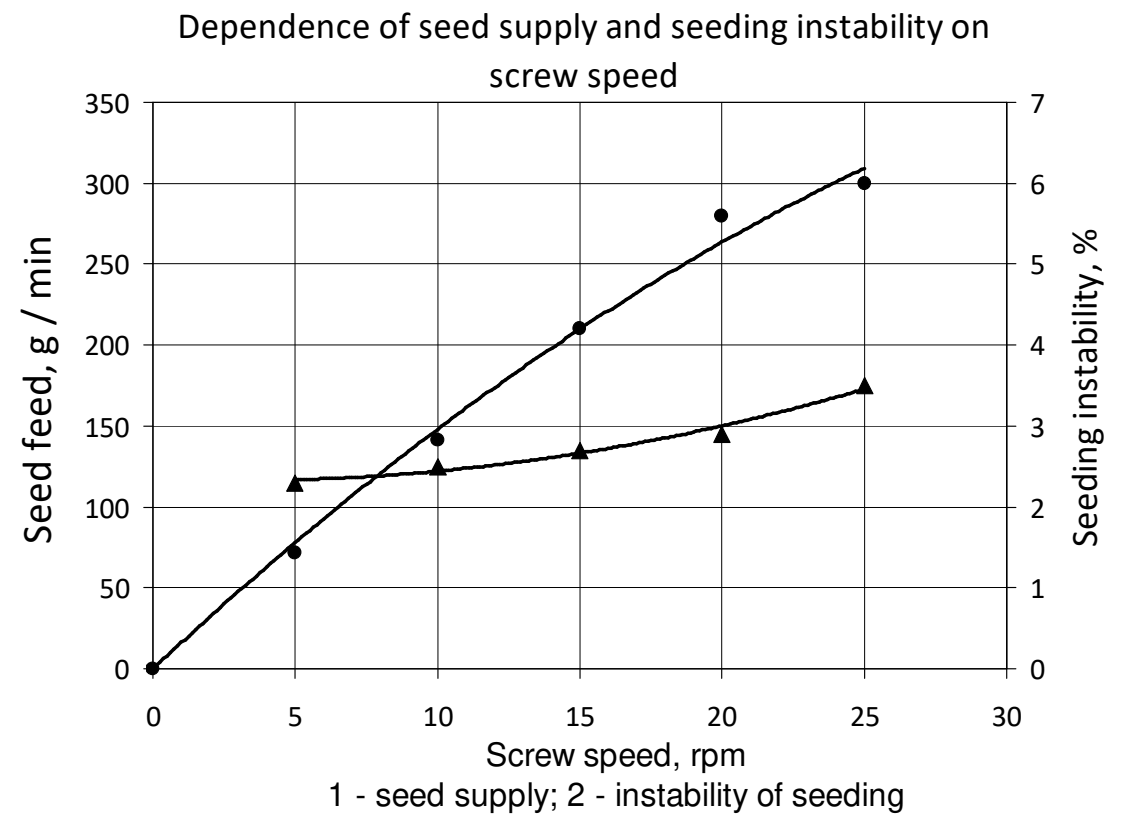

Fig. 4. Dependences of the seed supply and the instability of the seeding of the auger sowing apparatus on the rotational speed of the auger

Graphical dependencies of the influence of the drive shaft speed on the performance of the seeding unit and the instability of seeding were built based on the research results (see Fig. 5).

Based on the results obtained, it can be concluded that the linear nature of the dependence of the feed on the rotational speed of the drive shaft in the range from 10 to $30 \mathrm{rpm}$. The subsequent decrease in feed with an increase in the rotational speed is explained by a decrease in the volume of sown material supplied by one torsion-pin group into the space of the seeding window. The maximum feed rate corresponds to rotational speed values close to $30 \mathrm{rpm}$.

At the same time, as can be seen from the presented graphical dependencies, the most stable dosing, with a seeding instability coefficient within $2.5-3 \%$, is observed when installing 4 torsion-pin groups in the range of drive shaft speeds from 5 to $30 \mathrm{rpm}$.

\section{Dependence of seed supply and seeding instability on drive shaft speed}

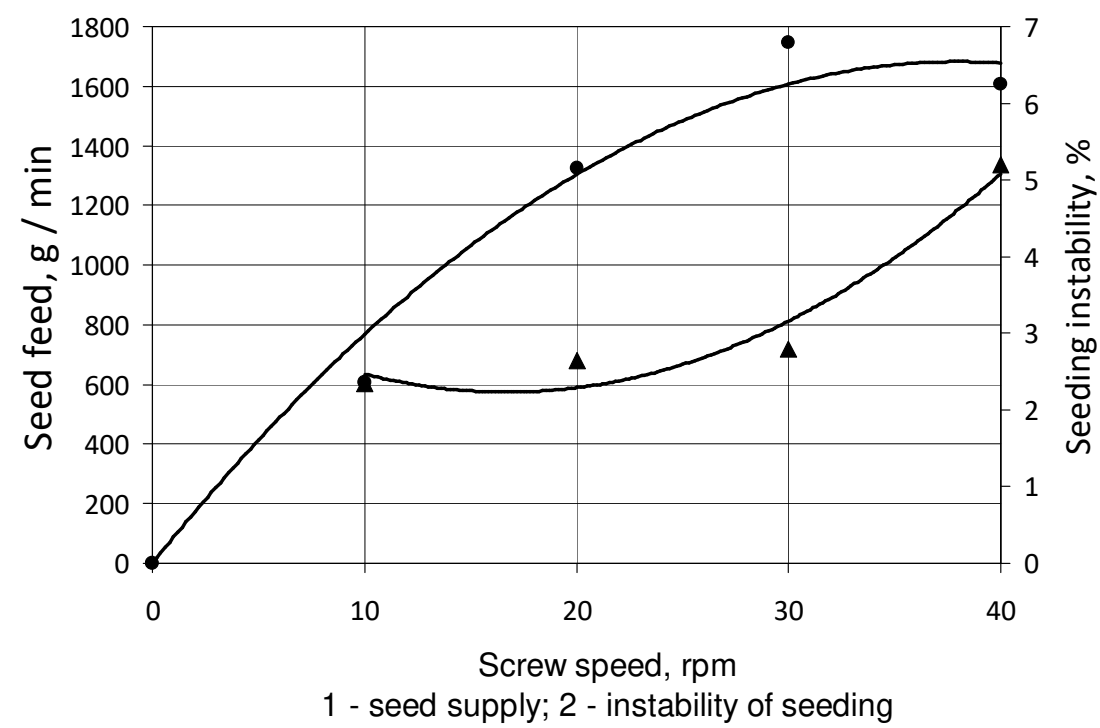

Fig. 5. Dependences of the seed supply and the instability of seeding of the torsion-pin sowing device on the rotational speed of the drive shaft 


\section{Conclusion}

As a result of the research carried out, operating hightech designs of seeding devices with a continuous dosing principle of the auger and torsion-pin types have been designed and manufactured. The sowing devices allow sowing loose and difficult-to-flow seeds when used as dispensers on a self-propelled pneumatic mini-seeder for sowing herbs in breeding production.

The analysis of the results of laboratory studies of the proposed seeding devices made it possible to determine the qualitative indicators of their work: at a rotational speed of the drive shaft of the torsion-pin seeding device up to $30 \mathrm{rpm}$, the most stable dosage is provided and the linear nature of the dependence of the seed supply remains. The highest productivity of the auger sowing apparatus was obtained at values of the auger rotation frequency close to $25 \mathrm{rpm}$, with a seeding instability index of $2.5 \ldots 3.5 \%$.

The developed seeding devices will significantly reduce the range of seeders and expand the range of sown seeds of various agricultural plants with one brand of seeding machine.

\section{References}

1. A.M. Petrov, V.A. Syrkin, The results of field studies of the experimental selecton seeder with a coil-pin seeding machine, Proc. of the Samara state agricultural Academy, 2, 36-39 (2017)

2. A.S. Firsov, M.V. Nikiforov, A.V. Kudryavtsev, A.S. Vasiliev, A.V. Dichensky, V.V. Golubev, Results of testing a disc pneumatic seed drill for flax, International Journal of Mechanical Engineering and Technology, 9(11), 1917-1925 (2018)
3. L. Wang, Y. Liao, Q. Liao, Design and experiment of remote control precision planter Forchinese cabbage vegetable, International Journal of Robotics and Automation, 33 (2018). DOI: 10.2316/Journal.206.2018.2.206-5536

4. V.A. Ovchinnikov, M.N. Chatkin, A.V. Ovchinnikova, Optimization of parameters and operating modes of a disk seeding apparatus according to the criterion of uniformity of seeding, Bulletin of the MordovianUniversity, 28(3), 379388 (2018)

5. A.G. Zubarev, N.P. Laryshin, A.V. Shukon, Development of working bodies for a grain seeder for sowing using resource-saving technologies, Science in the Central Russia, 3(39), 78-83 (2019)

6. O.N. Kukharev, N.P. Larushin, A device for guiding of bodies of irregular shape, Research J. of Pharmaceutical, Biological and Chemical Sciences, 9(3), 30-33 (2018)

7. Y.M. Isaev, N.M. Semashkin, Spiral-Screwing Device for Graining of Grain Material, Int. J. of Mechanical Engineering and Technology, 9(2), 622-628 (2018)

8. A. Zubarev, N. Larushin, O. Kukharev, Innovative working bodies of openers for seeding grain crops, Scientific papers-series a-agronomy, 63(1), 148-152 (2020)

9. Y.A. Saveliev, N.P. Kryuchin, D.N. Kotov, A.N. Kryuchin, Patent No. 133677, Russian Federation, IPC A01C 7/00. Sowing apparatus. No. 2013121148/13; declared 05/07/2013; publ. 10/27/2013, Bulletin No. 30.

10. N.P. Kryuchin, O.N. Serobaba, D.N. Kotov, A.N. Kryuchin, Patent No. 181167. Russian Federation, IPC A01C 7/00. Screw sowing apparatus. No. 2018106609, declared 02/21/2018; publ. 07/05/2018, Bull. No. 19. 